\title{
CHARACTERIZATION OF AN $H^{*}$-ALGEBRAS IN TERMS OF A TRACE
}

\section{PARFENY SAWOROTNOW}

\author{
(Received 6 March 2000)
}

\begin{abstract}
Arbitrary proper $H^{*}$-algebra is characterized in terms of the trace defined on a certain subset of the algebra.

2000 Mathematics Subject Classification. 46K15, 46K10.
\end{abstract}

This paper deals with characterizations of an arbitrary proper (not necessarily commutative) $H^{*}$-algebra. More specifically, we show that any Banach *-algebra with a partially defined trace, and some additional properties, has a Hilbert space structure with respect to which it is an $H^{*}$-algebra. In the past, the author worked in characterizations of commutative $H^{*}$-algebras (e.g., [3, 4]). As in [3], we do not assume both the existence of an inner product and the commutativity.

Now, we state our first result.

THEOREM 1. Let $A$ be a Banach algebra with an involution $x \rightarrow x^{*}, x \in A$, such that $\left\|x^{*}\right\|=\|x\|$. Assume that the set $A^{2}=\{x y: x, y \in A\}$ has a complex valued trace, that is, there is a complex valued function tr on $A^{2}$ with the following properties:

(i) if $x, y$, and $x+y$ belong to $A^{2}$, then $\operatorname{tr}(x+y)=\operatorname{tr} x+\operatorname{tr} y$,

(ii) $\operatorname{tr}(\lambda x)=\lambda \operatorname{tr} x$ for all $x \in A^{2}$ and any complex number $\lambda$,

(iii) $\operatorname{tr}\left(x^{*} x\right) \geq 0$ and $\operatorname{tr} x^{*} x=0$ if and only if $x=0, x \in A$,

(iv) $\operatorname{tr} x^{*}=\overline{\operatorname{tr}} x$ for all $x \in A^{2}$.

Suppose also that

(v) $\operatorname{tr}(x y)=\operatorname{tr}(y x)$ for all $x, y \in A$,

(vi) $|\operatorname{tr}(x y)| \leq\|x\| \cdot\|y\|$ for all $x, y \in A$,

(vii) for each bounded linear functional $f\left(f \in A^{*}\right)$, there exists $a \in A$ such that $f(x)=\operatorname{tr}\left(x a^{*}\right)$ for all $x \in A$.

Then $A$ is a proper $H^{*}$-algebra with respect to some scalar product whose corresponding norm || || is equivalent to the original norm. This means that there exists a scalar product (, ) on $A$ such that $A$ is an $H^{*}$-algebra with respect to this scalar product (and the original involution) and such that $k_{1}\|x\|^{2} \leq(x, x) \leq k_{2}\|x\|^{2}$ for some $k_{1}, k_{2} \geq 0$ and all $x \in A$ (and $(x y, z)=\left(y, x^{*} z\right)=\left(x, z y^{*}\right)$ for all $\left.x, y, z \in A\right)$.

REMARK 2. Note that each proper $H^{*}$-algebra $A$ has all the properties stated in Theorem 1 [5].

Proof of TheOrem 1. For any $x, y \in A$, let $(x, y)=\operatorname{tr}\left(x y^{*}\right)=\operatorname{tr}\left(y^{*} x\right)$. Then (, ) is an inner product on $A$ [6] (in the terminology of Loomis [1], ( , ) is a scalar product). Let \|\|$_{2}$ be the corresponding norm, $(x, x)=\|x\|_{2}^{2}, x \in A$. 
We show that $A$ is complete with respect to this new norm \|\|$_{2}$. Let $\left\{a_{n}\right\}$ be a Cauchy sequence, $\lim _{m, n}\left\|a_{n}-a_{m}\right\|_{2}=0$. Then there exists $M>0$ such that $\left\|a_{n}\right\|_{2} \leq M$ for all $n$ (every Cauchy sequence is bounded). For any fixed $x \in A$, the sequence $\left\{\operatorname{tr}\left(x a_{n}^{*}\right)\right\}$ of complex numbers is also Cauchy

$$
\left(\left|\operatorname{tr}\left(x a_{n}^{*}\right)-\operatorname{tr}\left(x a_{n}^{*}\right)\right| \leq\|x\|_{2}\left\|a_{n}-a_{m}\right\|_{2}\right) .
$$

So there is a complex number $\lambda_{x}$ such that $\operatorname{tr}\left(x a_{n}^{*}\right) \rightarrow \lambda_{x}, n \rightarrow \infty$. Define the complex valued function $f$ on $A$ by setting $f(x)=\lambda_{x}$. It follows from

$$
f(x)=\lim \operatorname{tr}\left(x a_{n}^{*}\right), \quad\left\|a_{n}\right\|_{2} \leq M,
$$

and the linearity of tr that $f$ is a bounded linear functional on $A\left(f \in A^{*}\right)$. Assumption (vii) in Theorem 1 implies that there exists $a \in A$ such that

$$
(x, a)=f(x)=\lim _{n} \operatorname{tr} x a_{n}^{*} .
$$

We show that $\lim _{n \rightarrow \infty}\left\|a_{n}-a\right\|_{2}=0$. Let $\epsilon>0$ be arbitrary, and let $n_{0}$ be such that $\left\|a_{n}-a_{m}\right\|_{2}<\epsilon / 2$ for all $n, m>n_{0}$. Let $n>n_{0}$ be fixed and arbitrary. The following relation:

$$
\begin{aligned}
\left\|a-a_{n}\right\|_{2}^{2} & =\left|\left(a-a_{n}, a-a_{m}\right)+\left(a-a_{n}, a_{m}-a_{n}\right)\right| \\
& =\left|\left(a-a_{n}, a\right)-\left(a-a_{n}, a_{m}\right)+\left(a-a_{n}, a_{m}-a_{n}\right)\right| \\
& \leq\left|f\left(a-a_{n}\right)-\left(a-a_{n}, a_{m}\right)\right|+\left\|a-a_{n}\right\|_{2} \cdot\left\|a_{n}-a_{m}\right\|_{2} \\
& \leq\left|f\left(a-a_{n}\right)-\left(a-a_{n}, a_{m}\right)\right|+\frac{\epsilon}{2}\left\|a-a_{n}\right\|_{2}
\end{aligned}
$$

shows that $\left\|a-a_{n}\right\|_{2}^{2} \leq \epsilon\left\|a-a_{n}\right\|_{2}$, since we can always find $m>n_{0}$ so that $\left|f\left(a-a_{n}\right)-\left(a-a_{n}, a_{m}\right)\right| \leq \epsilon / 2\left\|a-a_{n}\right\|_{2}$. Hence, $\left\|a-a_{n}\right\|_{2} \leq \epsilon$ for any $n>n_{0}$. This proves that $A$ is complete in this new norm \|\|$_{2}$.

It follows from (vi) that $\|x\|_{2} \leq\|x\|\left((x, x) \leq\|x\|\left\|x^{*}\right\|=\|x\|^{2}\right.$ for all $\left.x \in A\right)$. Closed graph theorem [1] tells us that \|\|$_{2}$ is equivalent to the original norm.

Now, it is an easy exercise to show that $A$ is an $H^{*}$-algebra with respect to the inner product (, ).

Now we state a slightly different characterization. It may not look like much of improvement over Theorem 1, but it allows for a larger class of examples. In fact, if we take any proper $H^{*}$-algebra $A$ and replace its norm by any other norm equivalent to the original one, we get a canonical example of a Banach algebra which both satisfies the conditions of the following theorem and is characterized by it.

THEOREM 3. Let $A$ be a Banach algebra with continuous involution $x \rightarrow x^{*}, x \in A$. Assume that the set $A^{2}=\{x y: x, y \in A\}$ has a trace tr with the following properties:

(i) if $x, y, x+y \in A^{2}$, then $\operatorname{tr}(x+y)=\operatorname{tr} x+\operatorname{tr} y$,

(ii) $\operatorname{tr}(\lambda x)=\lambda \operatorname{tr} x$ for all $x \in A^{2}$ and each complex number $\lambda$,

(iii) $\operatorname{tr}\left(x^{*} x\right) \geq 0$ and $\operatorname{tr}\left(x^{*} x\right)=0$ if and only if $x=0(x \in A)$,

(iv) $\operatorname{tr} x^{*}=\overline{\operatorname{tr}} x, x \in A^{2}$,

(v) $\operatorname{tr}(x y)=\operatorname{tr}(y x)$ for all $x, y \in A$. 
Assume further that

(vi)' for each $a \in A$ the map $T_{a}: x \rightarrow \operatorname{tr}\left(x a^{*}\right)\left(=T_{a}(x)\right)$ is continuous $\left(T_{a} \in A^{*}\right.$ for each $a \in A$ ),

(vii) for each bounded linear functional $f\left(f \in A^{*}\right)$ there exists $a \in A$ such that $f(x)=\operatorname{tr}\left(x a^{*}\right)$ for all $x \in A$.

Then $A$ has a structure of a proper $H^{*}$-algebra with respect to some scalar product (, ) such that $k\|x\|^{2} \leq(x, x) \leq K\|x\|^{2}$ for all $x \in A$ and some $k, K>0$.

REMARK 4. Note that (vi)' is equivalent to the following condition:

(vi)" there exists $M>0$ such that $|\operatorname{tr}(x y)| \leq M\|x\| \cdot\|y\|$ for all $x, y \in A$.

It is a consequence of uniform boundness theorem [6, page 239]. Proof of this fact is similar to the proof of Lemma 1 in [2]. Note also that continuity of involution implies that there exists $B>0$ such that $\left\|x^{*}\right\| \leq B\|x\|, x \in A$.

Proof of Theorem 3. We leave it to the reader to modify the proof of Theorem 1 in order to verify validity of Theorem 3 .

\section{REFERENCES}

[1] L. H. Loomis, An Introduction to Abstract Harmonic Analysis, D. Van Nostrand Company, New York, 1953. MR 14,883c. Zbl 052.11701.

[2] P. P. Saworotnow, On continuity of multiplication in a complemented algebra, Pacific J. Math. 14 (1964), 1399-1403. MR 30\#2361. Zbl 154.15102.

[3] _ A simple characterization of commutative $H^{*}$-algebras, Int. J. Math. Math. Sci. 22 (1999), no. 4, 885-888. MR 2000i:46045. Zbl 991.48198.

[4] _ An exotic characterization of a commutative $H^{*}$-algebra, Int. J. Math. Math. Sci. 24 (2000), no. 1, 1-4. CMP 1773 964. Zbl 991.64627.

[5] P. P. Saworotnow and J. C. Friedell, Trace-class for an arbitrary $H^{*}$-algebra, Proc. Amer. Math. Soc. 26 (1970), 95-100. MR 42\#2304. Zbl 197.39701.

[6] G. F. Simmons, Introduction to Topology and Modern Analysis, McGraw-Hill Book Co., New York, 1963. MR 26\#4145. Zbl 105.30603.

PARFENY SAWOROTNOW: DePARTMENT OF MATHEMATICS, CATHOLIC UNIVERSITY OF AMERICA, WASHINGTON, DC 20064, USA

E-mail address: saworotnow@cua.edu 


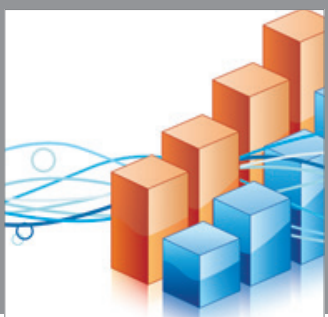

Advances in

Operations Research

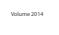

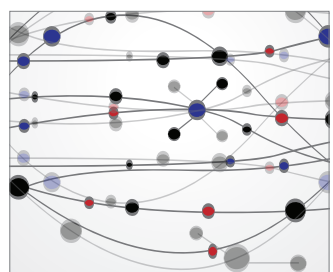

\section{The Scientific} World Journal
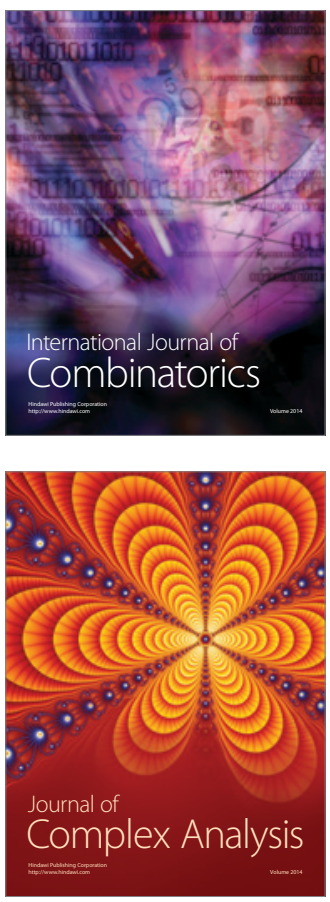

International Journal of

Mathematics and

Mathematical

Sciences
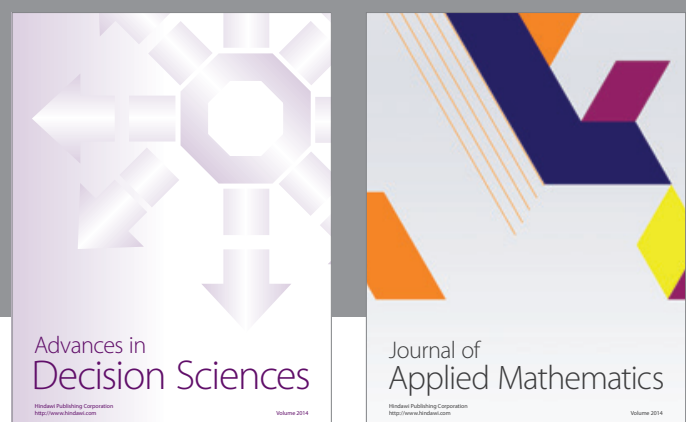

Journal of

Applied Mathematics
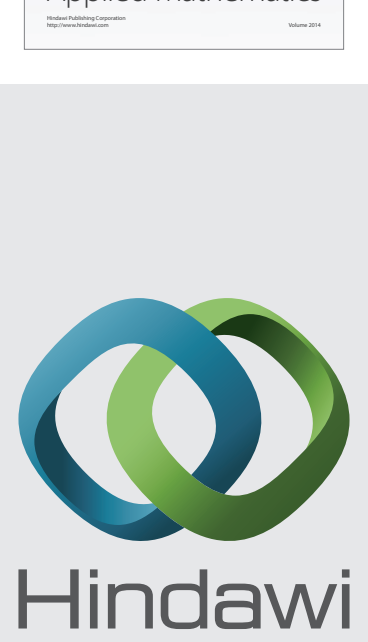

Submit your manuscripts at http://www.hindawi.com
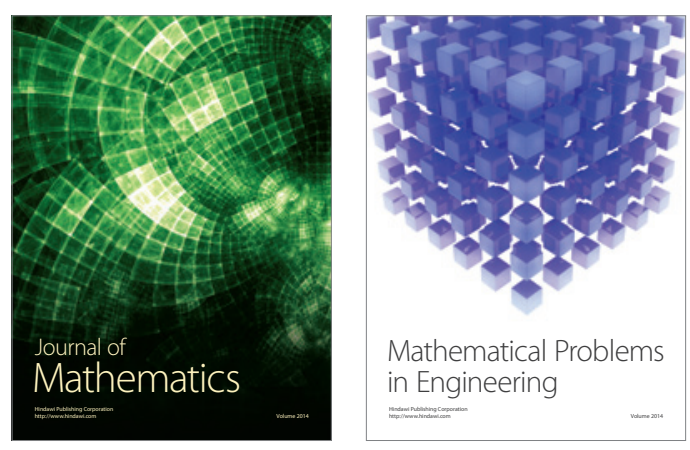

Mathematical Problems in Engineering
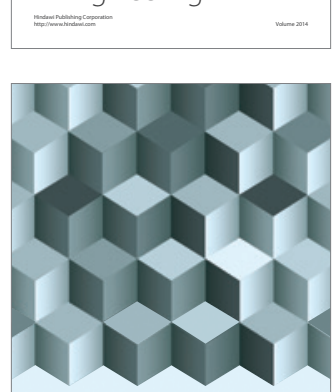

Journal of

Function Spaces
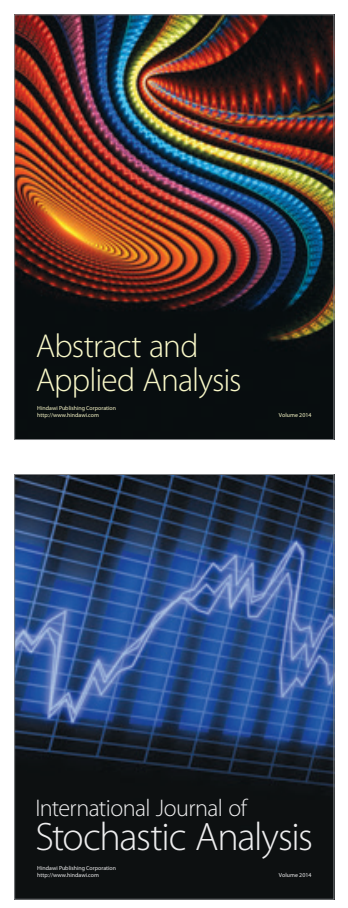

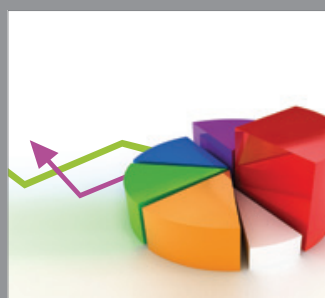

ournal of

Probability and Statistics

Promensencen
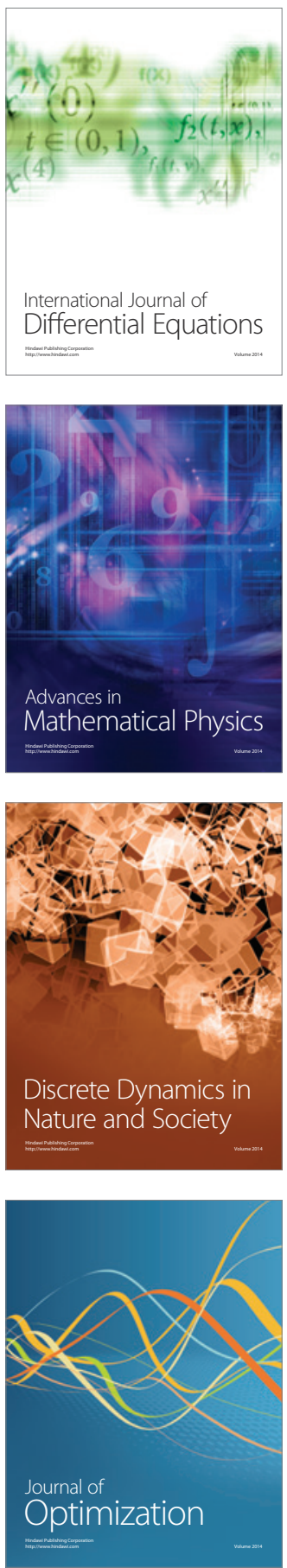